\title{
Effect of exercise intensity on postprandial lipemia, markers of oxidative stress and endothelial function after a high-fat meal
}

\begin{tabular}{|c|c|}
\hline Journal: & Applied Physiology, Nutrition, and Metabolism \\
\hline Manuscript ID & apnm-2016-0262.R2 \\
\hline Manuscript Type: & Article \\
\hline Date Submitted by the Author: & 22-Aug-2016 \\
\hline Complete List of Authors: & $\begin{array}{l}\text { Krüger, Renata; Universidade Federal do Rio Grande do Sul, Program of } \\
\text { Human Movement Sciences, Faculty of Physical Education, Physiotherapy } \\
\text { and Dance (ESEFID); University of Calgary, Faculty of Kinesiology } \\
\text { Teixeira, Bruno; Universidade Federal do Rio Grande do Sul, Program of } \\
\text { Human Movement Sciences, Faculty of Physical Education, Physiotherapy } \\
\text { and Dance (ESEFID); Universidade Regional Integrada do Alto Uruguai e } \\
\text { das Missões, Physical education } \\
\text { Farinha, Juliano; Universidade Federal do Rio Grande do Sul, Program of } \\
\text { Human Movement Sciences, Faculty of Physical Education, Physiotherapy } \\
\text { and Dance (ESEFID) } \\
\text { Macedo, Rodrigo; Universidade Federal do Rio Grande do Sul, Program of } \\
\text { Human Movement Sciences, Faculty of Physical Education, Physiotherapy } \\
\text { and Dance (ESEFID) } \\
\text { Boeno, Francesco; Universidade Federal do Rio Grande do Sul, Program of } \\
\text { Human Movement Sciences, Faculty of Physical Education, Physiotherapy } \\
\text { and Dance (ESEFID) } \\
\text { Rech, Anderson; Universidade Federal do Rio Grande do Sul, Program of } \\
\text { Human Movement Sciences, Faculty of Physical Education, Physiotherapy } \\
\text { and Dance (ESEFID) } \\
\text { Lopez, Pedro; Universidade Federal do Rio Grande do Sul, Program of } \\
\text { Human Movement Sciences, Faculty of Physical Education, Physiotherapy } \\
\text { and Dance (ESEFID) } \\
\text { Pinto, Ronei; Universidade Federal do Rio Grande do Sul, Program of } \\
\text { Human Movement Sciences, Faculty of Physical Education, Physiotherapy } \\
\text { and Dance (ESEFID) } \\
\text { Reischak-Oliveira, Alvaro; Universidade Federal do Rio Grande do Sul, } \\
\text { Program of Human Movement Sciences, Faculty of Physical Education, } \\
\text { Physiotherapy and Dance (ESEFID) }\end{array}$ \\
\hline Keyword: & $\begin{array}{l}\text { Postprandial responses, oxidative damage, lipid peroxidation, } \\
\text { nitrites/nitrates, flow-mediated dilatation }\end{array}$ \\
\hline
\end{tabular}


SCHOLARONE $^{m}$
Manuscripts

https://mc06.manuscriptcentral.com/apnm-pubs 
Effect of exercise intensity on postprandial lipemia, markers of oxidative stress and endothelial function after a high-fat meal

Renata Lopes Krüger MSc ${ }^{1,2}$, Bruno Costa Teixeira PhD ${ }^{1,3}$, Juliano Boufleur Farinha $\mathrm{MSc}^{1}$, Rodrigo Cauduro Oliveira Macedo MSc ${ }^{1}$, Francesco Pinto Boeno BPhEd ${ }^{1}$, Anderson Rech MSc ${ }^{1}$, Pedro Lopez BPhEd ${ }^{1}$, Ronei Silveira Pinto PhD ${ }^{1}$ and Alvaro Reischak-Oliveira $\mathrm{PhD}^{1}$

${ }^{1}$ Program of Human Movement Sciences, Faculty of Physical Education, Physiotherapy and Dance (ESEFID), Federal University of Rio Grande do Sul (UFRGS), 750 Felizardo Street, Porto Alegre, Rio Grande do Sul, Brazil, 90690-200.

Corresponding author: MSc. Renata Lopes Krüger; Faculty of Kinesiology, University of Calgary (UofC), 2500 University Drive NW, Calgary, Alberta, Canada T2N 1 N4.

Telephone: (403) 220 3497;

Email: renata.kruger@ucalgary.ca

${ }^{2}$ Faculty of Kinesiology, University of Calgary, 2500 University Dr NW, Calgary, AB T2N $1 \mathrm{~N} 4$.

${ }^{3}$ Physical Education School, Universidade Regional Integrada do Alto Uruguai e das Missões, 3149 José Bonifácio Street, São Luiz Gonzaga, Rio Grande do Sul, Brazil, 97800-000. 


\section{Abstract}

Purpose: The aim of this study was to compare the effect of two different exercise intensities on postprandial lipemia, oxidative stress markers and endothelial function after a high-fat meal (HFM).

Material and methods: Eleven young men completed 2-day trials in three conditions: Rest, moderate-intensity exercise (MI-Exercise) and heavy-intensity exercise (HIExercise). Subjects performed an exercise bout or no exercise (Rest) on the evening of day 1 . On the morning of day 2 , a HFM was provided. Blood was sampled at fasting ( 0 h) and every hour from 1 to $5 \mathrm{~h}$ during the postprandial period for triacylglycerol (TAG), thiobarbituric acid reactive substance (TBARS) and nitrite/nitrate (NOx) concentrations. Flow-mediated dilatation (FMD) was also analyzed.

Results: TAG concentrations were reduced in exercise conditions compared to Rest during the postprandial period $(P<0.004)$. TAG incremental area under the curve (iAUC) was smaller after HI-Exercise compared with Rest $(P=0.012)$. TBARS concentrations were reduced in MI-Exercise compared to Rest $(P<0.041)$. FMD was higher in exercise conditions than Rest at $0 \mathrm{~h}(\mathrm{P}<0.02)$ and NOx concentrations were enhanced in MI-Exercise compared to Rest at $0 \mathrm{~h}(\mathrm{P}<0.01)$.

Conclusions: These results suggest that acute exercise can reduce lipemia after a HFM. However, HI-Exercise showed to be more effective in reducing iAUC TAG, which might suggest higher protection against postprandial TAG enhancement. Conversely, MI-Exercise can be beneficial to attenuate the susceptibility of oxidative damage induced by a HFM and to increase endothelial function in the fasted state compared to Rest. 
Keywords: Postprandial responses, oxidative damage, lipid peroxidation, nitrites/nitrates, flow-mediated dilatation. 


\section{Introduction}

Regular consumption of a high-fat meal (HFM) can increase circulating triacylglycerol (TAG) concentration and contribute to the long-term development of cardiovascular diseases, even in healthy young men (Bae et al. 2001; Tushuizen et al. 2006). Moreover, the consumption of a HFM produces an imbalance in postprandial metabolism, increasing the susceptibility of oxidative damage and vascular endothelial dysfunction (Wallace et al. 2010). The increase in reactive oxygen species production enhances peroxynitrite ( $\left.\mathrm{ONOO}^{-}\right)$formation and, by consequence, decreases nitric oxide (NO) bioavailability, causing endothelial dysfunction (Forstermann and Munzel 2006; Wallace et al. 2010). While direct assessment of NO is extremely difficult, the combination of nitrites/nitrates (NOx), NO end-products, is widely used to indirectly estimate NO production (Casey et al. 2007). Another extensively-used technique to evaluate endothelial function is flow-mediated dilatation (FMD) of the brachial artery in response to hyperemia (Tyldum et al. 2009; Wallace et al. 2010; Sedgwick et al. 2013; Sedgwick et al. 2014).

In this sense, previous studies have shown that exercise performed a few hours before the consumption of a HFM can attenuate oxidative damage and endothelial dysfunction induced by the meal (Bae et al. 2001; Clegg et al. 2007; Mc Clean et al. 2007; Jenkins et al. 2011; Krüger et al. 2015). However, only few studies have investigated the effect of exercise intensity (Tyldum et al. 2009; Gabriel et al. 2012; Canale et al. 2014). For instance, Tyldum et al. (2009) tested the effect of two different aerobic exercise intensities with the same energy expenditure (at $85-90 \%$ and at 60 $70 \%$ of maximal heart rate (HR)). Total antioxidant status (TAS) was increased after 
both exercise sessions compared with rest, but the high-intensity exercise increased the antioxidant status more. In addition, FMD was increased in both exercise conditions compared to rest (Tyldum et al. 2009). Gabriel et al. (2012) also compared the effect of two different exercise intensities with different energy expenditures (high-intensity interval cycling vs. continuous walking for $30 \mathrm{~min}$ ). The authors reported that thiobarbituric acid reactive substance (TBARS) concentrations were decreased after the HFM only in the interval cycling condition, which had lower energy expenditure compared to the walking condition. Conversely, Canale et al. (2014) analyzed the effect of three intensities of cycling exercise (60 min, $60 \mathrm{~s}$ and $15 \mathrm{~s}$ ) and did not find any difference between conditions for lipid peroxidation.

It is evident that there is a gap in the literature that cannot explain the effect of exercise intensity on postprandial oxidative stress and endothelial function responses. Different exercise methodologies have been tested and the results are contradictory. It is known that to analyze the effect of the exercise intensity, the exercise bouts need to be matched in terms of energy expenditure, considering that the energy expenditure during an exercise session can affect the postprandial metabolism responses (Pettit and Cureton 2003). The only previous study that have matched the energy expenditure between both exercise intensities sessions (Tyldum et al. 2009) did not directly evaluated any prooxidant stress markers. In addition, the exercise intensities were prescribed based on the $\% \mathrm{HR}$, which it is a less reliable method to prescribe individualized exercise compared to the ventilatory threshold based method (Wolpern et al. 2015). 
Answering this scientific question about the effect of exercise intensity on the postprandial metabolism is crucial because exercise intensity is an important component of training prescription. Therefore, to clarify this question, the purpose of this study was to compare the effect of two different isoenergetic aerobic exercise intensities determinate by the ventilatory threshold based method (moderate and heavy) on postprandial lipemia (PPL), oxidative stress markers and endothelial function after the consumption of a HFM. Based on the previous study done by Tyldum et al. (2009), we hypothesized that exercise performed at heavy-intensity would cause a greater attenuation of PPL and prooxidant stress markers and increase both antioxidant defense and FMD response than moderate-intensity exercise.

\section{Materials and methods}

\section{Study population}

Eleven healthy young men volunteered to participate in this study. To be included in this study, all participants were required to be physically active (exercise at least three times a week), eutrophic (body mass index: $18.5-25 \mathrm{~kg} / \mathrm{m}^{2}$ ) and have a $\mathrm{VO}_{2 \max }$ greater than $35 \mathrm{~mL} / \mathrm{kg} / \mathrm{min}$. Smokers, participants who were receiving medical treatment or had any history of severe disease related to lipid metabolism were excluded. All participants provided written informed consent. This study was conducted according to the guidelines laid down in the Declaration of Helsinki and was approved by the ethics committee of the Federal University of Rio Grande do Sul, Brazil.

\section{Preliminary visit}


At the preliminary visit all participants performed an analysis of basal metabolic rate $(\mathrm{BMR})$, body composition and $\mathrm{VO}_{2 \max }$. The $\mathrm{BMR}$ analysis consisted in 30 min of exhaled gas collection in dorsal decubitus performed during the first morning hours (between 7.00 and $8.30 \mathrm{am}$ ) while exhaled gases were analyzed by a breath-by-breath collection system (Quark CPET, COSMED, Rome, Italy). The first 10 min of gas collection were excluded from the analysis; thus, $\mathrm{VO}_{2}$ and $\mathrm{VCO}_{2}(\mathrm{~L} / \mathrm{min})$ obtained during the final 20 min of each collection (mean value of the period) were used for the calculation of BMR. BMR was calculated according to the Weir equation (Weir 1949) and then converted to BMR for a 24-h period. Prior to this analysis, participants were asked to fast for $12 \mathrm{~h}$ and to have a good night sleep of at least $8 \mathrm{~h}$. Furthermore, they were strongly encouraged to avoid moderate to high energy expenditure activities $24 \mathrm{~h}$ before the BMR analysis. The marking of the anatomical sites and measurement technique of skinfolds followed the standards of the International Society for the Advancement of Kinanthropometry (ISAK). Body composition was calculated using a five-component method (Marfell-Jones et al. 2006). An incremental exercise test was conducted to determine $\mathrm{VO}_{2 m a x}$ using the breath-by-breath method and an open-circuit spirometry system (Quark CPET, COSMED, Rome, Italy). The progressive exercise test was performed on a treadmill and lasted for 8 - 12 min according to the recommendations of the American College of Sports Medicine (ACSM) (ACSM 2009). The test ended if the participant reached volitional exhaustion, respiratory exchange ratio $(\mathrm{RER}) \geq 1.15$ or $\mathrm{HR} \geq 95 \%$ of age-predicted maximum. The first ventilatory threshold $\left(\mathrm{VT}_{1}\right)$ was identified as the minimum workload at which the ventilatory equivalent ratio for oxygen $\left(\mathrm{VE} / \mathrm{VO}_{2}\right)$ systematically increased without an increase in the 
ventilatory equivalent ratio for carbon dioxide $\left(\mathrm{VE} / \mathrm{VCO}_{2}\right)$ and the second ventilatory threshold $\left(\mathrm{VT}_{2}\right)$ as the lowest workload where both $\mathrm{VE} / \mathrm{VO}_{2}$ and $\mathrm{VE} / \mathrm{VCO} \mathrm{O}_{2}$ increased. $\mathrm{VO}_{2 \max }$ was determined when a plateau in the $\mathrm{VO}_{2}$ occurred when further increase of exercise intensity. The plateau was considered when the $\mathrm{VO}_{2}$ varied by less than 1.5 $\mathrm{mL} / \mathrm{kg} / \mathrm{min}$ even with an increase in the workload (Cunha et al. 2011). VT $1, \mathrm{VT}_{2}$ and $\mathrm{VO}_{2 \max }$ were obtained by visual inspection of graphs by 3 independent observers.

\section{Intervention}

After the preliminary visit, the participants were randomly assigned to perform 2day trials in three different conditions (interspaced by at least one week):

(i) Rest: the participant rested for $45 \mathrm{~min}$;

(ii) Moderate-intensity exercise (MI-Exercise): the participant ran on a treadmill at a speed corresponding to $\mathrm{VT}_{1}$;

(iii) Heavy-intensity exercise (HI-Exercise): the participant ran on a treadmill at a speed corresponding to $10 \%$ below $\mathrm{VT}_{2}$.

The exercise-intensities were defined based on the "intensity domain" model described by Hill et al. (2002), in which moderate intensity is associated with an increase in $\mathrm{VO}_{2}$ to a steady state (i.e. close to $\mathrm{VT}_{1}$ ), whereas heavy intensity corresponds to work rates close to the lactate threshold or $\mathrm{VT}_{2}$ (Hill et al. 2002). Both exercise bouts were monitored online by an open-circuit spirometry system. The exercise duration was determined to correspond to $15 \%$ of the BMR in kcal. This value corresponded to an average of $306.2 \pm 28.2 \mathrm{kcal} / \mathrm{per}$ session of MI-Exercise and 298.4 $\pm 27.8 \mathrm{kcal} / \mathrm{per}$ session of HI-Exercise and it met the ACSM recommendations 
associated with lower rate of cardiovascular disease, which it is about $1000 \mathrm{kcal} /$ week or $150 \mathrm{~min} /$ week performed on $\geq 3$ days/week (Garber et al. 2011). Both exercise bouts were isoenergetic and were monitored online by an open-circuit spirometry system (Quark CPET, COSMED, Rome, Italy). The energy expenditure during exercise was calculated based on the metabolic equivalent method (Ainsworth et al. 2000). The energy expenditure was calculated at the end of every minute and exercise stopped once the target energy expenditure had been completed.

On the evening of day 1 , participants performed one of the three different conditions. Ten minutes after the protocol a standard meal was provided. Participants then went home and were instructed to fast, have a good night sleep and to avoid physical activity for the following $12 \mathrm{~h}$. In the early morning (day 2), participants arrived at the laboratory for a fasted blood collection and FMD analysis (0 h). A HFM was then provided and blood samples were taken every hour during the postprandial period (from 1 to $5 \mathrm{~h}$ after the meal consumption). Additional FMD analyses were performed at 1 and $3 \mathrm{~h}$.

\section{Diet Control}

To eliminate the confounder effects of food consumption on analyzed parameters, a 24-h diet recall interview was performed by a nutritionist during day 2 of each trial. This interview consisted of recording the amount of food and beverage consumed during day 1. After the first condition, participants were asked to follow the same diet for the other conditions to avoid intraindividual variance between the conditions. 
The standard meal consisted of a four-cheese pizza and a maltodextrin beverage. The percentage of each macronutrient was: $60 \%$ carbohydrate, $20 \%$ lipid and $20 \%$ protein. The HFM was white sandwich bread with table cream and mozzarella cheese and fat milk with chocolate powder. The percentage of each macronutrient was: $35 \%$ carbohydrate, $50 \%$ lipid and $15 \%$ protein. Previous studies have shown that the minimal absolute lipid load that leads to significant changes on TAG can vary between 30 and $50 \mathrm{~g}$ (Cohen and Schall 1988; Dubois et al. 1998). In this study, 50\% of energy from fat provided an average of $52.4 \mathrm{~g}$ fat. The size of both meals was individually calculated to be equivalent in energy to $50 \%$ of daily BMR. The participants had between $10-20$ min to ingest each meal.

\section{Blood collection and biochemistry}

Blood samples $(0-5 h)$ were collected every hour from the arm antecubital region via a disposable sterile cannula. At $0,1,3$ and $5 \mathrm{~h}$, blood was collected to analyze TAG, total cholesterol, high-density lipoprotein cholesterol (HDL-C), low-density lipoprotein cholesterol (LDL-C), glucose, insulin, TBARS, NOx and total thiols. At 2 and $4 \mathrm{~h}$, blood was taken to analyze TAG only. Blood samples were collected in tubes containing EDTA and then centrifuged at $1500 \mathrm{rpm}$ for $15 \mathrm{~min}$ at $4{ }^{\circ} \mathrm{C}$. The plasma was stored and frozen at $-80{ }^{\circ} \mathrm{C}$ until analysis.

TAG, total cholesterol, HDL-C and glucose were analyzed using an automatic colorimetric method (Cobas C111 analyzer, Roche, Basel, Switzerland). LDL-C was calculated from the Friedewald equation (Friedewald et al. 1972). Insulin concentrations 
were determined by ELISA with standard test kits (ref. EIA-2935, DRG International, Springfield, United States), according to the manufacturer's instructions.

The NOx concentrations were analyzed according to a previously described methodology by Miranda et al. (2001). The samples were analyzed in a microplate reader (Multiskan Go, Thermo Scientific, Vantaa, Finland) with the specified wavelength of $540 \mathrm{~nm}$ and the results were expressed in $\mu \mathrm{M} / \mathrm{L}$. TBARS concentrations were analyzed following a previously described technique by Ohkawa et al. (1979). The samples were analyzed in a microplate reader at $532 \mathrm{~nm}$ and the results were expressed in $\mu \mathrm{M}$ of MDA/L. Total thiols analysis was performed according to a methodology described by Ellman (1959). The samples were analyzed in a microplate reader at $412 \mathrm{~nm}$ and the results were expressed in $\mathrm{mM}$ of $\mathrm{GSH} / \mathrm{L}$.

\section{Arterial flow-mediated dilatation (FMD)}

FMD analysis consisted of acquiring images of the brachial artery using a 7.5 $\mathrm{MHz}$ linear array transducer ultrasound system (Nemio XG, Toshiba, Japan). A rapid inflation/deflation pneumatic cuff was positioned distal to the olecranon to create an ischemic stimulus. Doppler flow velocity measurements were obtained simultaneously using the lowest possible angle to interrogate maximum laminar flow. Participants remained at rest for $15 \mathrm{~min}$ before $30 \mathrm{~s}$ of baseline analysis of arterial diameter and blood flow were performed. Subsequently, the cuff was inflated (> $240 \mathrm{mmHg}$ ) for $5 \mathrm{~min}$. Arterial diameter and blood flow were recorded on video tape at least $30 \mathrm{~s}$ prior to cuff deflation and for 2 min immediately after. The videotape was later analyzed by two 
independent blinded observers according to published instructions (Corretti et al. 2002). The results are expressed in \%FMD variation from baseline.

\section{Statistical Analysis}

The Shapiro-Wilk test was used to assess the normality of data for each variable. Levene's test was used to test the homogeneity of variance assumption. Mauchly's test was used to assess the sphericity assumption. When sphericity was violated, the Greenhouse-Geisser correction factor was applied. Parametric data are presented as mean \pm standard deviation (SD) and the non-parametric data (NOx) are presented as median [quartile 1 (Q1), quartile 3 (Q3)]. Differences between exercise bouts variables were assessed by paired t-test. A one-way analysis of variances (ANOVA) was performed to analyze the effect of macronutrient intake from the 24-h diet recalls between the conditions. All blood outcomes (except NOx) and FMD data were analyzed using a two-way ANOVA ( 3 conditions and 6 times) with repeated-measures. If results showed a significant main effect for condition or time, a subsequent Bonferroni post-hoc analysis was used to identify differences between conditions or times. If there was an interaction between condition and time, a series of paired $t$-tests with Holm-Bonferroni corrections was used to compare different conditions and time points (Holm 1979). The area under the curve (AUC) for TAG was calculated using the trapezoidal method, whereas the incremental area under the curve (iAUC) was calculated by the same method, but subtracting fasting levels from each postprandial response. The difference between conditions for AUC and iAUC was analyzed using a one-way ANOVA. For NOx, the Kruskal-Wallis test was used to perform intergroup (3 conditions) comparisons 
at each time point. Time-point comparisons were performed by Friedman test. A 95\% level of confidence was predetermined as the minimum criterion to denote a statistical difference $(P<0.05)$. The data was analyzed using the Statistical Package for Social Sciences version 19.0 (SPSS Inc., Chicago, United States). Using Altman`s nomogram (Altman 1982), the total sample size calculation for the outcome AUC TAG was 11 participants, assuming a standardized difference of 1.07 (Gabriel et al. 2012), a power of 0.8 and a significance level of 0.05 .

\section{Results}

The characteristics of the participants are presented in Table 1. There were no differences between the conditions for reported energy and macronutrient intake from the 24-h diet recalls $(P>0.05)$ (Table 2$)$. There were no differences in energy expenditure between MI-Exercise and HI-Exercise (306.2 $\pm 28.2 \mathrm{kcal}$ vs. $298.4 \pm 27.8$ kcal; $\mathrm{P}>0.05)$. The average and the percentage of $\mathrm{VO}_{2}$ during exercise were lower in MI-Exercise than HI-Exercise $(31 \pm 4 \mathrm{~mL} / \mathrm{kg} / \mathrm{min}$ and $65 \pm 3 \%$ vs. $37 \pm 4 \mathrm{~mL} / \mathrm{kg} / \mathrm{min}$ and $77 \pm 2 \% ; \mathrm{P}<0.01)$. Exercise duration was longer in Ml-Exercise than HI-Exercise (37.5 \pm 4.7 min vs. $32.5 \pm 3.9$ min; $\mathrm{P}<0.01$ ), whereas mean $\mathrm{HR}$ was higher in HI-Exercise than MI-Exercise $(165.5 \pm 8.1$ beats per minute $(\mathrm{bpm})$ vs. $157.6 \pm 6.6 \mathrm{bpm} ; \mathrm{P}=0.02)$.

\section{Biochemistry and endothelial responses}

The two-way ANOVA test showed no significant interaction between conditions and time for any of the blood outcomes. There was a condition effect for TAG concentrations $\left(F_{2,20}=22.082 ; P<0.001\right)$. The Bonferroni post-hoc test showed a 
difference between MI-Exercise and Rest $(\mathrm{P}<0.004)$ and between $\mathrm{HI}-\mathrm{Exercise}$ and Rest $(P<0.001)$ (Fig. 1A). There was also a significant time effect $\left(F_{5,50}=15.988 ; P<\right.$ 0.001). TAG concentrations showed significantly higher value from 2 to $5 \mathrm{~h}$ compared to $0 \mathrm{~h}(\mathrm{P}<0.032)$. There was also an increase in TAG concentrations from 1 to $2 \mathrm{~h}(\mathrm{P}=$ $0.041)$ and a decrease from 2 and $3 \mathrm{~h}$ compared to $5 \mathrm{~h}(\mathrm{P}<0.044)$.

The one-way ANOVA reveled a difference between the conditions for TAG AUC $\left(F_{2,32}=8.488 ; P<0.001\right) . T A G$ AUC was $29 \%$ smaller after HI-Exercise compared with Rest $(P<0.01)$ and $21 \%$ smaller after Ml-Exercise compared with Rest $(P=0.017)$ (Fig. 1B). The one-way ANOVA reveled also a difference between the conditions for iAUC TAG $\left(F_{2,32}=5.038 ; P=0.013\right)$. The iAUC TAG was $49 \%$ smaller after HI-Exercise compared with Rest $(P=0.012)$ (Fig. 1C).

There was no main effect of condition and time for total cholesterol $(P>0.05)$. There was also no main effect of condition for LDL-C, HDL-C, glucose or insulin ( $P$ > 0.05) (Table 3). There was a main effect of time for $L D L-C\left(F_{5,50}=8.410 ; P<0.001\right)$. LDL-C concentrations were lower at 1,3 and $5 \mathrm{~h}$ compared to $0 \mathrm{~h}(\mathrm{P}<0.016)$. There was a main effect of time for HDL-C $\left(F_{5,50}=5.546 ; P<0.001\right)$. There was a decrease in HDL-C concentrations from 0 to $5 \mathrm{~h}(\mathrm{P}<0.001)$. There was also a time effect for glucose $\left(F_{3,30}=16.763 ; P<0.001\right)$ and Insulin $\left(F_{3.30}=83.001 ; P<0.001\right)$. Glucose concentrations decreased from 0 to $1 \mathrm{~h}(P=0.002)$ and from 1 to $3 \mathrm{~h}(P=0.012)$, whereas Insulin concentrations increased from 0 to $1 \mathrm{~h}(P<0.001)$ and decreased from 1 to $3 \mathrm{~h}(\mathrm{P}<0.001)$ (Table 3$)$.

There was a significant main effect of condition for TBARS $\left(F_{2,20}=5.880 ; P=\right.$ 0.012) (Fig. 2). The Bonferroni post-hoc test showed a significant difference between 
MI-exercise and Rest $(P=0.041)$. There was also a significant time effect for TBARS ( $F$ 3,30 =6.393; $P=0.002)(F i g .2)$. The post hoc analysis showed difference between 0 and $3 \mathrm{~h}$ for TBARS $(P=0.007)$. There was no main effect of condition and time for total thiols $(P>0.05)$. A Kruskal-Wallis test revealed a significant difference for fasting NOx concentrations between MI-Exercise and Rest $(P<0.01)$ (Fig. 3). A Friedman test revealed no significant difference between the repeated measures (time) NOx concentrations.

The two-way ANOVA showed an interaction between the conditions and time for FMD $\left(F_{4,40}=3.850 ; P=0.019\right)$. The paired sample $t$-test analysis showed a different dilatation between MI-Exercise and Rest at $0 \mathrm{~h}(\mathrm{P}=0.02)$ and between $\mathrm{HI}$-Exercise and Rest at $0 \mathrm{~h}(\mathrm{P}=0.008)$ (Fig. 4). There was also a difference from 0 to $3 \mathrm{~h}$ and from 1 to $3 \mathrm{~h}$ in the Rest condition $(\mathrm{P}<0.02)$ and from 0 to $1 \mathrm{~h}$ in the HI-Exercise condition $(\mathrm{P}=$ 0.015). It is important to mention that there was no difference in mean basal diameter of the artery between the three conditions $(P>0.05)$.

\section{Discussion}

The purpose of this study was to compare the effect of two different intensities of isoenergetic exercise on PPL, oxidative stress markers and endothelial function after a HFM. The main findings of this study are: (i) both exercise intensities reduce TAG concentrations after a HFM; and (ii) MI-Exercise causes a lower oxidative stress marker response and a greater endothelial function in the fasted state compared to Rest.

Independent of exercise intensity, a prior single bout of exercise reduced postprandial TAG concentrations compared to Rest. This is in agreement with previous 
findings showing that single exercise bouts with equal energy expenditure cause similar reductions in postprandial TAG concentrations (Burnett et al.1993; Miyashita et al. 2006; Ferreira et al. 2011). Although both exercise intensities were effective in minimizing the AUC TAG concentrations in this study, iAUC TAG was 49\% lower in the $\mathrm{HI}$-Exercise than Rest. Recent studies have shown that iAUC is an accurate method to describe TAG responses after the consumption of a HFM, since this method subtracts the fasting concentrations from all postprandial concentrations in order to evaluate just the postprandial rise in TAG (Freese et al. 2014). Thus, the lower iAUC TAG in the HIExercise condition compared to Rest suggests that high-intensity exercise offers more protection against the postprandial TAG enhancement (Freese et al. 2014). This larger reduction of iAUC TAG in HI-Exercise after the HFM may be important for clinical applications such as exercise prescription. It is likely that HI-Exercise enabled TAG clearance over a greater amount of time than MI-Exercise and thus, may be more effective in reducing the long-term risk for cardiovascular diseases. A plausible explanation for the enhanced TAG clearance after high-intensity exercises is the greater activation of muscle lipoprotein lipase (Trombold et al. 2013). There are some evidences showing that the lipoprotein lipase plays an essential role in plasma TAG clearance (Kersten 2014). However, the reduction in the synthesis and secretion of liver-derived very-low-density lipoprotein cholesterol (VLDL-C) and the increase in chylomicron and VLDL-C clearance after exercise can also play an important role in this process (Malkova et al. 2000). Thus, these factors together might have contributed to increase TAG clearance in this condition. 
For insulin, there was an increase in the concentrations from 0 to 1 and $3 \mathrm{~h}$ during the postprandial state, as expected after a HFM (Zhang et al. 2007; Miyashita et al. 2008). Conversely, concentrations of glucose decreased during the postprandial period. Because there was no effect of condition, this time effect appears to be a consequence of the increase in insulin concentrations at this same time. There were no differences between conditions for LDL-C, HDL-C, glucose and insulin levels. These results support previous studies that also did not find difference between exercise and rest conditions on these variables concentrations during the postprandial period (Clegg et al. 2007; Gabriel et al. 2012).

We hypothesized that HI-Exercise would promote greater benefits on PPL and on the response of oxidative stress markers after a HFM. This study demonstrated that a single bout of exercise can attenuate TAG concentrations during the postprandial period, independent of exercise intensity. However, just the MI-Exercise decreased TBARS concentrations compared to Rest condition. TBARS concentrations increased from 0 to $3 \mathrm{~h}$ after the consumption of a HMF. This result is in accordance with previous studies that show that TBARS concentrations are enhanced during the postprandial period (Gabriel et al. 2012; Canale et al. 2014). Despite this fact, TBARS concentrations were reduced only in MI-Exercise condition compared to Rest. Therefore, different exercise intensities may cause distinct effects on lipid peroxidation. The HI-Exercise was performed at $\mathrm{VO}_{2}$ approximately $15 \%$ higher than MI-Exercise. It is known that exercise performed at higher intensities contributes to an increase in reactive oxygen species production due to increased depletion of energy substrates and/or a disturbed redox state (Lovlin et al. 1987; Vollaard et al. 2005). Conversely, the lower intensity of 
the Ml-Exercise condition might not be sufficient to increase reactive oxygen species production and to cause an increase in the oxidative stress marker evaluated in this study. Thus, acutely, MI-Exercise produces a lower oxidative stress damage.

NOx concentrations and FMD responses did not differ between conditions during the postprandial period. This is in agreements with a similar study done by Mc Clean et al. (2007), in which no difference in NOx concentrations between exercise and rest during the postprandial period was observed. According to Mc Clean et al. (2007), the acute benefits of the exercise might occur despite of changes in NOx concentrations in postprandial state. Regarding FMD responses, there are two main explanations that may explain our results. Firstly, there is an evidence showing that NOx concentrations are well-correlated with brachial FMD responses in young adults (Casey et al. 2007). So, despite some studies having shown exercise-induced increases in \%FMD after a HFM (Tyldum et al. 2009; Sedgwick et al. 2013; Sedgwick et al. 2014), the absence of changes in FMD response in the present study may be explained by the unchanged NOx concentrations. Secondly, the studies cited above evaluated different populations (adolescents and middle-aged men) and it is known that people from different age and training status present groups have different FMD responses. For instance, physically active and inactive men can present different FMD responses following a HFM (Johnson et al. 2011). While inactive men have a lower postprandial FMD response, FMD reamains unchanged after a HFM in active men (Johnson et al. 2011). Since in the present study the participants were physically active, habitual physical activity may have attenuated endothelial impairments induced by the meal. 
MI-Exercise also induced an increase in fasting NOx concentrations. It is known that when exercise is performed at $50 \%$ of $\mathrm{VO}_{2 \max }$ (i.e. approximately the intensity of MIExercise) NOx production is increased. However, at higher intensities $\left(75 \%\right.$ of $\left.\mathrm{VO}_{2 \max }\right)$, exercise can reduce NOx production due to greater reactive oxygen species production (Goto et al. 2003). As a result, exercise performed at moderate intensity can have a beneficial effect maintaining higher NOx plasmatic concentrations that can be observed up to $12 \mathrm{~h}$ after the exercise session. There was also an increase in FMD at $0 \mathrm{~h}$ for both exercise intensities compared to Rest. For MI-Exercise the increase in FMD corresponded to a similar increase in NOx. Conversely, FMD responses in HI-Exercise cannot be explained by higher concentrations of NOx. A possible explanation is that higher reactive oxygen species production after the exercise bout might have contributed to increase $\mathrm{ONOO}^{-}$formation and, by consequence, decrease NO production. As a result, stable NO end-products were unchanged. The increase on FMD in $\mathrm{HI}$-Exercise might be explained by increases in other vasoactive mediators that were not measured in this study.

There are a couple of limitations that need to be addressed. First, the combination of NOx and FMD analyses have been widely used to indirectly estimate NO production and vasodilation of the brachial artery, respectively, in response to hyperemia. However, both techniques have limitations regarding sensitivity, variability and reproducibility. Second, one of the main limitations of this study was the nonmeasurement of other cardiovascular risk markers. For instance, we did not find a statistical difference for total thiols between the conditions. This group of organic components represents about half of the total antioxidant defense in humans, 
nevertheless, other components also play an important role to defend our organism against prooxidant agents such as TAS and vitamins C and E (Erel 2004). Thus, a clear limitation of this study was to not evaluate any of these parameters.

In summary, in young health men, a single aerobic exercise bout performed $12 \mathrm{~h}$ before the consumption of a HFM can attenuate TAG concentrations, suggesting that aerobic exercise can reduce lipemia independent of exercise intensity (moderate or heavy). However, HI-Exercise showed to be more effective in reducing iAUC TAG, which might suggest that this exercise intensity offers more protection against the postprandial TAG enhancement. It is known that regular exercise is an important strategy to decrease oxidative damage risk induced by a high-fat diet and also to reduce the long-term development of cardiovascular diseases. This study has shown that, acutely, MI-Exercise can be beneficial to attenuate the susceptibility of oxidative damage induced by a HFM compared to Rest. Other potential benefits of MI-Exercise are the increase in fasting NOx concentrations and the vasodilation response which likely indicate lower oxidative stress damage and greater endothelial function in the fasted state due to the exercise bout. However, more studies must be done to confirm this statement.

\section{Conflict of interest}

The authors declare that there are no conflicts of interest.

\section{Acknowledgments}


The authors thank Gabriel Fonseca for assistance during the data collection and John Temesi for his assistance in reviewing this article for English.

\section{References}

ACSM. 2009. Guidelines for Exercise Testing and Prescription; Eighth Edition; Wolters Kluwer Health. Lippincott Willians \& Wilkins, Baltimore, USA.

Ainsworth, B.E., Haskell, W.L., Whitt, M.C., Irwin, M.L., Swartz, A.M., Strath, S.J., O'Brien, W.L., Bassett, D.R., Jr., Schmitz, K.H., Emplaincourt, P.O., Jacobs, D.R., Jr., and Leon, A.S. 2000. Compendium of physical activities: an update of activity codes and MET intensities. Med. Sci. Sports Exerc. 32(9): 498-504. doi:10.1097/00005768-200009001-00009.

Altman, D.G. 1982. Statistics in medical journals. Stat. Med. 1(1): 59-71.

Bae, J.H., Bassenge, E., Kim, K.B., Kim, Y.N., Kim, K.S., Lee, H.J., Moon, K.C., Lee, M.S., Park, K.Y., and Schwemmer, M. 2001. Postprandial hypertriglyceridemia impairs endothelial function by enhanced oxidant stress. Atherosclerosis 155(2): 517-523. doi: 10.1016/S0021-9150(00)00601-8.

Burnett, H.E., Aldred, H.E. and Hardman, A.E. 1993. Influence of the intensity of prior exercise on postprandail lipaemia in man. Proc. Nutr. Soc. 52(3): 284A.

Canale, R.E., Farney, T.M., McCarthy, C.G., and Bloomer, R.J. 2014. Influence of acute exercise of varying intensity and duration on postprandial oxidative stress. Eur. J. Appl. Physiol. 114(9): 1913-1924. doi: 10.1007/s00421-014-2912-z.

Casey, D.P., Beck, D.T., and Braith, R.W. 2007. Systemic plasma levels of nitrite/nitrate (NOx) reflect brachial flow-mediated dilation responses in young men and women. 
Clin. Exp. Pharmacol. Physiol. 34(12): 1291-1293. doi: 10.1111/j.14401681.2007.04715.x.

Clegg, M., McClean, C., Davison, W.G., Murphy, H.M., Trinick, T., Duly, E., McLaughlin, J., Fogarty, M., and Shafat, A. 2007. Exercise and postprandial lipaemia: effects on peripheral vascular function, oxidative stress and gastrointestinal transit. Lipids Health. Dis. 6: 30. doi: 10.1186/1476-511X-6-30.

Cohen, J.C., and Schall, R. 1988. Reassessing the effects of simple carbohydrates on the serum triglyceride responses to fat meals. Am. J. Clin. Nutr. 48(4): 1031-1034. Corretti, M.C., Anderson, T.J., Benjamin, E.J., Celermajer, D., Charbonneau, F., Creager, M.A., Deanfield, J., Drexler, H., Gerhard-Herman, M., Herrington, D., Vallance, P., Vita, J., and Vogel, R. 2002. Guidelines for the ultrasound assessment of endothelial-dependent flow-mediated vasodilation of the brachial artery: a report of the International Brachial Artery Reactivity Task Force. J. Am. Coll. Cardiol. 39(2): 257-265. doi: 10.1016/S0735-1097(01)01746-6.

Cunha, G., Lorenzi, T., Sapata, K., Lopes, A.L., Gaya, A.C., and Oliveira, Á. 2011. Effect of biological maturation on maximal oxygen uptake and ventilatory thresholds in soccer players: an allometric approach. J. Sports Sci. 29(10): 10291039. doi: $10.1080 / 02640414.2011 .570775$.

Dubois, C., Beaumier, G., Juhel, C., Armand, M., Portugal, H., Pauli, A.M., Borel, P., Latgé, C., Lairon, D. Effects of graded amounts $(0-50 \mathrm{~g})$ of dietary fat on postprandial lipemia and lipoproteins in normolipidemic adults. Am. J. Clin. Nutr. 67(1): 31-38. 
Ellman, G.L. 1959. Tissue sulfhydryl groups. Arch. Biochem. Biophys. 82(1): 70-77. doi: 10.1016/0003-9861(59)90090-6.

Erel, O. 2004. A novel automated direct measurement method for total antioxidant capacity using a new generation, more stable ABTS radical cation. Clin. Biochem. 37(4): 277-285. doi: 10.1016/j.clinbiochem.2003.11.015.

Ferreira, A.P., Ferreira, C.B., Souza, V.C., Cordova, C.O., Silva, G.C., Nobrega Ode, T., and Franca, N.M. 2011. The influence of intense intermittent versus moderate continuous exercise on postprandial lipemia. Clinics (Sao Paulo) 66(4): 535-541. doi: 10.1590/S1807-59322011000400003.

Forstermann, U. and Munzel, T. 2006. Endothelial nitric oxide synthase in vascular disease: from marvel to menace. Circulation 113(13): 1708-1714. doi: 10.1161/CIRCULATIONAHA.105.602532.

Freese, E.C., Gist, N.H., and Cureton, K.J. 2014. Effect of prior exercise on postprandial lipemia: an updated quantitative review. J. Appl. Physiol. 116(1): 67-75. doi: 10.1152/japplphysiol.00623.2013.

Friedewald, W.T., Levy, R.I., and Fredrickson, D.S. 1972. Estimation of the concentration of low-density lipoprotein cholesterol in plasma, without use of the preparative ultracentrifuge. Clin. Chem. 18(6): 499-502.

Gabriel, B., Ratkevicius, A., Gray, P., Frenneaux, M.P., and Gray, S.R. 2012. Highintensity exercise attenuates postprandial lipaemia and markers of oxidative stress. Clin. Sci. (Lond) 123(5): 313-321. doi: 10.1042/CS20110600.

Garber, C.E., Blissmer, B., Deschenes, M.R., Franklin, B.A., Lamonte, M.J., Lee, I.M., Nieman, D.C., and Swain, D.P. 2011. American College of Sports Medicine 
position stand. Quantity and quality of exercise for developing and maintaining cardiorespiratory, musculoskeletal, and neuromotor fitness in apparently healthy adults: guidance for prescribing exercise. Med. Sci. Sports. Exerc. 43(7): 13341359. doi: 10.1249/MSS.0b013e318213fefb.

Goto, C., Higashi, Y., Kimura, M., Noma, K., Hara, K., Nakagawa, K., Kawamura, M., Chayama, K., Yoshizumi, M., and Nara, I. 2003. Effect of different intensities of exercise on endothelium-dependent vasodilation in humans: role of endotheliumdependent nitric oxide and oxidative stress. Circulation 108(5): 530-535. doi: 10.1161/01.CIR.0000080893.55729.28.

Hill, D.W., Poole, D.C., and Smith, J.C. 2002. The relationship between power and the time to achieve VO(2max). Med. Sci. Sports Exerc. 34(4): 709-714. doi: 10.1097/00005768-200204000-00023.

Holm, S. 1979. A simple sequentially rejective multiple test procedure. Scand. J. Statist. 6: 65-70.

Jenkins, N.T., Landers, R.Q., Thakkar, S.R., Fan, X., Brown, M.D., Prior, S.J., Spangenburg, E.E., and Hagberg, J.M. 2011. Prior endurance exercise prevents postprandial lipaemia-induced increases in reactive oxygen species in circulating CD31+ cells. J. Physiol. 589(Pt 22): 5539-5553. doi:

10.1113/jphysiol.2011.215277.

Johnson, B.D., Padilla, J., Harris, R.A., and Wallace, J.P. 2011. Vascular consequences of a high-fat meal in physically active and inactive adults. Appl. Physiol. Nutr. Metab. 36(3): 368-375. doi: 10.1139/h11-028. 
Kersten, S. 2014. Physiological regulation of lipoprotein lipase. Biochim. Biophys. Acta. 1841(7): 919-933. doi: 10.1016/j.bbalip.2014.03.013.

Krüger, R.L., Farinha, J.B., Teixeira, B.C., and Reischak-Oliveira, A. 2015. Oxidative stress and endothelial function: effects of physical exercise on results of postprandial lipemia. J. Vasc. Bras. 14(4): 328-340. doi: 10.1590/16775449.01715.

Lovlin, R., Cottle, W., Pyke, I., Kavanagh, M., and Belcastro, A.N. 1987. Are indices of free radical damage related to exercise intensity. Eur. J. Appl. Physiol. Occup. Physiol. 56(3): 313-316. doi: 10.1007/BF00690898.

Malkova, D., Evans, R.D., Frayn, K.N., Humphreys, S.M., Jones, P.R., and Hardman, A.E. 2000. Prior exercise and postprandial substrate extraction across the human leg. Am. J. Physiol. Endocrinol. Metab. 279(5): 1020-1028.

Marfell-Jones, M., Olds, T., Stewart, A.D., and Carter, L. 2006. Kinanthropometry IX Proceedings of the 9th international conference of the International Society for the Advancement of Kinanthropometry. Routledge, London.

Mc Clean, C.M., Mc Laughlin, J., Burke, G., Murphy, M.H., Trinick, T., Duly, E., and Davison, G.W. 2007. The effect of acute aerobic exercise on pulse wave velocity and oxidative stress following postprandial hypertriglyceridemia in healthy men. Eur. J. Appl. Physiol. 100(2): 225-234. doi: 10.1007/s00421-007-0422-y.

Miranda, K.M., Espey, M.G., and Wink, D.A. 2001. A rapid, simple spectrophotometric method for simultaneous detection of nitrate and nitrite. Nitric Oxide 5(1): 62-71. doi: 10.1006/niox.2000.0319. 
Miyashita, M., Burns, S.F., and Stensel, D.J. 2006. Exercise and postprandial lipemia: effect of continuous compared with intermittent activity patterns. Am. J. Clin. Nutr. 83(1): 24-29.

Miyashita, M., Burns, S.F., and Stensel, D.J. 2008. Accumulating short bouts of brisk walking reduces postprandial plasma triacylglycerol concentrations and resting blood pressure in healthy young men. Am. J. Clin. Nutr. 88(5): 1225-1231.

Ohkawa, H., Ohishi, N., and Yagi, K. 1979. Assay for lipid peroxides in animal tissues by thiobarbituric acid reaction. Anal. Biochem. 95(2): 351-358. doi: 10.1016/00032697(79)90738-3.

Petitt, D.S., and Cureton, K.J. 2003. Effects of Prior Exercise on Postprandial Lipemia: A Quantitative Review. Metabolism, 52(4): 418-424. doi: 10.1053/meta.2003.50071.

Sedgwick, M.J., Morris, J.G., Nevill, M.E., and Barrett, L.A. 2014. Effect of repeated sprints on postprandial endothelial function and triacylglycerol concentrations in adolescent boys. J. Sports Sci. 33(8): 806-816. doi: $10.1080 / 02640414.2014 .964749$.

Sedgwick, M.J., Morris, J.G., Nevill, M.E., Tolfrey, K., Nevill, A., and Barrett, L.A. 2013. Effect of exercise on postprandial endothelial function in adolescent boys. Br. J. Nutr. 110(2): 301-309. doi: 10.1017/S0007114512004977.

Trombold, J.R., Christmas, K.M., Machin D.R., Kim, I.Y., and Coyle, E.F. 2013. Acute high-intensity endurance exercise is more effective than moderate-intensity exercise for attenuation of postprandial triglyceride elevation. J. Appl. Physiol. (1985). 15(114): 792-800. doi: 10.1152/japplphysiol.01028.2012. 
Tushuizen, M.E., Nieuwland, R., Scheffer, P.G., Sturk, A., Heine, R.J., and Diamant, M. 2006. Two consecutive high-fat meals affect endothelial-dependent vasodilation, oxidative stress and cellular microparticles in healthy men. J. Thromb. Haemost. 4(5): 1003-1010. doi: 10.1111/j.1538-7836.2006.01914.x.

Tyldum, G.A., Schjerve, I.E., Tjonna, A.E., Kirkeby-Garstad, I., Stolen, T.O., Richardson, R.S., and Wisloff, U. 2009. Endothelial dysfunction induced by postprandial lipemia: complete protection afforded by high-intensity aerobic interval exercise. J. Am. Coll. Cardiol. 53(2): 200-206. doi: 10.1016/j.jacc.2008.09.033. Vollaard, N.B., Shearman, J.P., and Cooper, C.E. 2005. Exercise-induced oxidative stress:myths, realities and physiological relevance. Sports Med. 35(12): 10451462.

Wallace, J.P., Johnson, B., Padilla, J., and Mather, K. 2010. Postprandial lipaemia, oxidative stress and endothelial function: a review. Int. J. Clin. Pract. 64(3): 389403. doi: 10.1111/j.1742-1241.2009.02146.x.

Weir, J.B. 1949. New methods for calculating metabolic rate with special reference to protein metabolism. J. Physiol. 109(1-2): 1-9. doi:

10.1113/jphysiol.1949.sp004363.

Wolpern, A.E., Burgos, D.J., Janot, J.M., and Dalleck, L.C. 2015. Is a threshold-based model a superior method to the relative percent concept for establishing individual exercise intensity? a randomized controlled trial. BMC Sports Sci. Med. Rehabil. 7(16): 1-9. doi: 10.1186/s13102-015-0011-z. 
Zhang, J.Q., Ji, L.L., Fogt, D.L., and Fretwell, V.S. (2007). Effect of exercise duration on postprandial hypertriglyceridemia in men with metabolic syndrome. J. Appl. Physiol. (1985) 103(4): 1339-1345. doi: 10.1152/japplphysiol.00181.2007. 
Table 1. Participants Characteristics

\begin{tabular}{ll}
\hline & $\begin{array}{l}\text { Participants } \\
(\mathrm{n}=11)\end{array}$ \\
\hline Age (years) & $23 \pm 3$ \\
Body mass $(\mathrm{kg})$ & $73.7 \pm 9.8$ \\
Height $(\mathrm{cm})$ & $177.0 \pm 1.0$ \\
BMl $\left(\mathrm{kg} / \mathrm{m}^{2}\right)$ & $23.3 \pm 2.4$ \\
BMR $(\mathrm{kcal} / \mathrm{day})$ & $1882.2 \pm 157.6$ \\
VO & \\
Muax $(\mathrm{mL} / \mathrm{kg} / \mathrm{min})$ & $47.7 \pm 6.1$ \\
Muscle mass $(\mathrm{kg})$ & $34.5 \pm 6.1$ \\
Fat mass $(\mathrm{kg})$ & $18.7 \pm 3.3$ \\
Sum of skinfolds $(\mathrm{mm})$ & $70.1 \pm 18.5$ \\
\hline
\end{tabular}

Values are arithmetic mean \pm SD. BMI: body metabolic index, BMR: basal metabolic rate, $\mathrm{VO}_{2 \max }$ : maximal oxygen uptake. Sum of skinfolds (triceps, subscapular, supraspinal, abdominal, thigh and medial calf). 
Table 2. Reported energy and macronutrient intake in the 24-h diet recall between experimental trials

\begin{tabular}{llll}
\hline & Rest & Ml-Exercise & HI-Exercise \\
\hline Energy Intake (kcal) & $2442 \pm 889$ & $2545 \pm 1341$ & $2167 \pm 481$ \\
Carbohydrate (\%) & $55 \pm 7$ & $53 \pm 15$ & $56 \pm 6$ \\
Carbohydrate (g) & $321 \pm 95$ & $337 \pm 85$ & $299 \pm 44$ \\
Protein (\%) & $19 \pm 4$ & $20 \pm 6$ & $20 \pm 3$ \\
Protein (g) & $110 \pm 31$ & $125 \pm 73$ & $111 \pm 36$ \\
Fat (\%) & $26 \pm 9$ & $27 \pm 11$ & $24 \pm 6$ \\
Fat (g) & $64 \pm 34$ & $71 \pm 29$ & $58 \pm 14$
\end{tabular}

No significant difference for reported energy and macronutrient intake $(P>0.05)$. Values are arithmetic mean \pm SD. MI-Exercise: moderate-intensity exercise, $\mathrm{HI}$ Exercise: heavy-intensity exercise. 
Table 3. Biochemical markers in the fasted state and following a high-fat meal

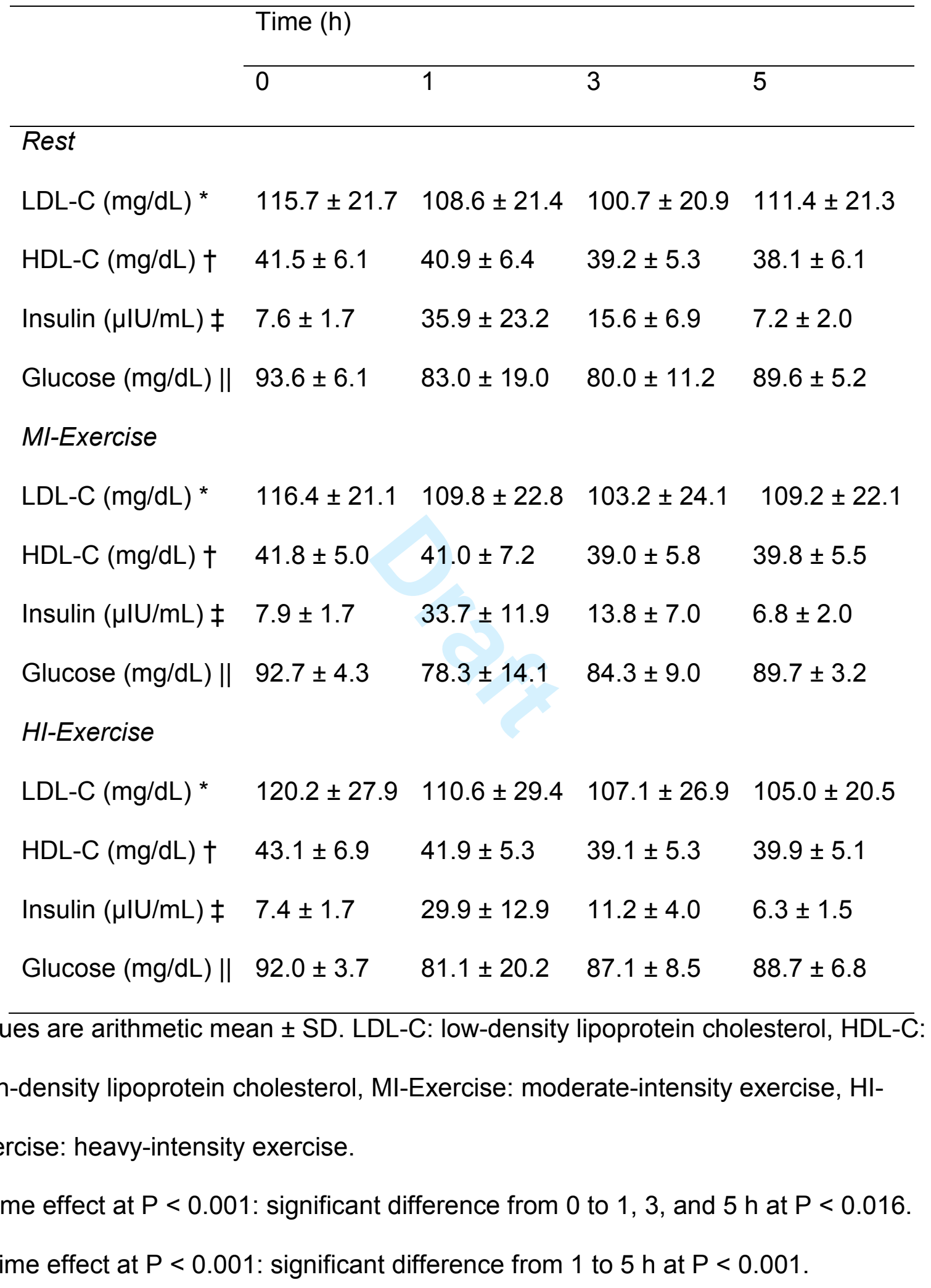


$\ddagger$ Time effect at $P<0.001$ : significant difference from 0 to $1 \mathrm{~h}$ at $\mathrm{P}<0.001$; significant difference from 1 to $3 \mathrm{~h}$ at $\mathrm{P}<0.001$.

$\|$ Time effect at $P<0.001$ : significant difference from 0 to $1 \mathrm{~h}$ at $\mathrm{P}=0.002$; significant difference from 1 to $3 \mathrm{~h}$ at $\mathrm{P}<0.001$. 


\section{Figures}

Fig. 1A. Plasma triacylglycerol (TAG) concentration during the experiment. Values are arithmetic mean \pm SD. MI-Exercise: moderate-intensity exercise, HI-Exercise: heavyintensity exercise.

* Time effect at $P<0.001$ : significant difference from 0 to $2,3,4$ and $5 \mathrm{~h}$ at $\mathrm{P}<0.032$; significant difference from 1 to $2 \mathrm{~h}$ at $\mathrm{P}=0.041$; significant difference from 2 and 3 to 5 $h$ at $\mathrm{P}<0.044$.

† Condition effect at $\mathrm{P}<0.001$ : significant difference from MI-Exercise to Rest at $\mathrm{P}=$ 0.004; significant difference from HI-Exercise to Rest at $\mathrm{P}<0.001$.

Fig. 1B. The AUC TAG concentration for each condition. Values are arithmetic mean \pm SD. MI-Exercise: moderate-intensity exercise, HI-Exercise: heavy-intensity exercise. * Condition effect at $\mathrm{P}<0.001$ : difference from MI-Exercise to Rest at $\mathrm{P}=0.017$; difference from $\mathrm{HI}$-Exercise and Rest at $\mathrm{P}<0.01$.

Fig. 1C. The iAUC TAG concentration for each condition. Values are arithmetic mean \pm SD. MI-Exercise: moderate-intensity exercise, HI-Exercise: heavy-intensity exercise.

${ }^{*}$ Condition effect at $\mathrm{P}=0.013$ : difference from $\mathrm{HI}-$ Exercise and Rest at $\mathrm{P}=0.012$.

Fig. 2. Plasma thiobarbituric acid reactive substance (TBARS) concentration during the experiment. Values are arithmetic mean \pm SD. MI-Exercise: moderate-intensity exercise, HI-Exercise: heavy-intensity exercise. 
* Time effect at $P=0.002$ : significant difference from 0 to $3 \mathrm{~h}$ at $\mathrm{P}=0.007$.

† Condition effect at $\mathrm{P}=0.012$ : significant difference from MI-Exercise to Rest at $\mathrm{P}=$ 0.041 .

Fig. 3. Plasma nitrite/nitrate (NOx) concentration during the experiment. Values are presented as median [Q1, Q3]. MI-Exercise: moderate-intensity exercise, HI-Exercise: heavy-intensity exercise.

† Kruskal-Wallis test: difference from MI-Exercise to Rest at $\mathrm{P}<0.01$.

Fig. 4. Flow-mediated dilatation (FMD) response during the experiment. Values are arithmetic mean \pm SD. MI-Exercise: moderate-intensity exercise, HI-Exercise: heavyintensity exercise.

Interaction between condition and time at $\mathrm{P}=0.019$.

* Significant difference from 0 to $3 \mathrm{~h}$ and from 1 to $3 \mathrm{~h}$ in the Rest condition at $\mathrm{P}<0.02$; significant difference from 0 to $1 \mathrm{~h}$ in the $\mathrm{HI}$-Exercise condition at $\mathrm{P}=0.015$. † Significant difference from MI-Exercise and Rest at $\mathrm{P}=0.02$; significant difference from $\mathrm{HI}$-Exercise and Rest at $\mathrm{P}=0.008$. 
A.

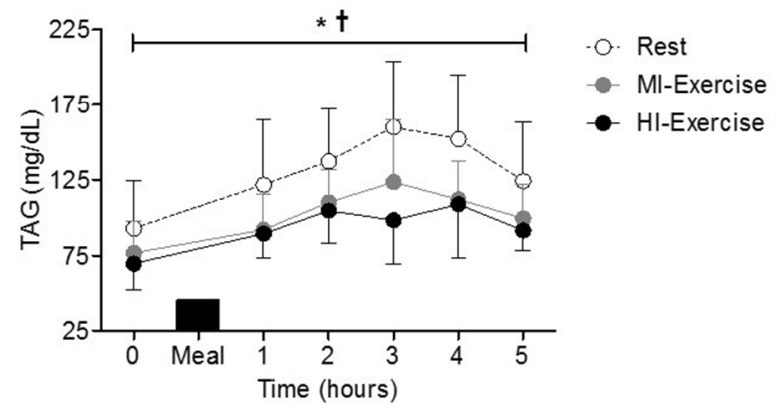

B.

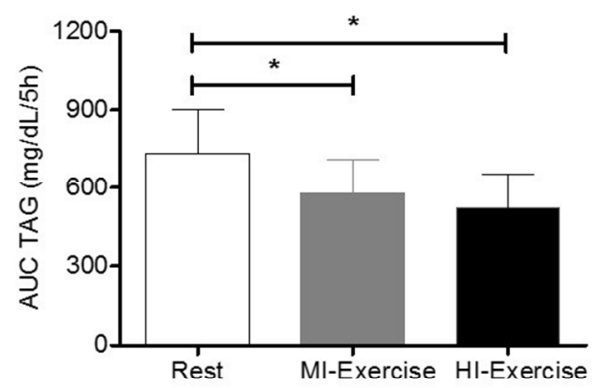

c.

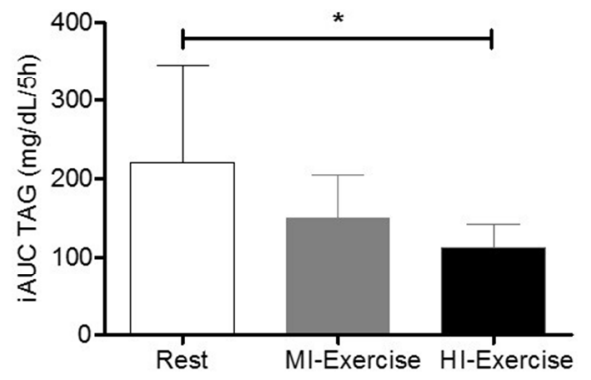

$60 \times 108 \mathrm{~mm}(300 \times 300 \mathrm{DPI})$ 


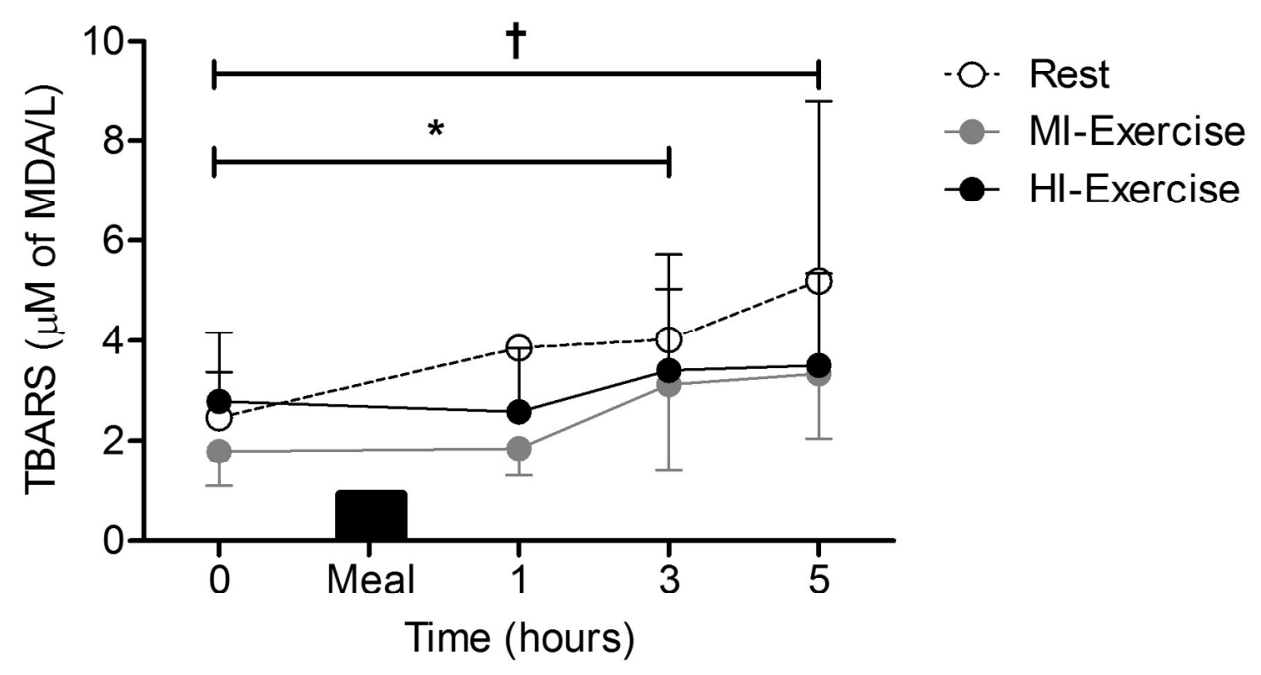

$160 \times 96 \mathrm{~mm}(300 \times 300$ DPI $)$ 


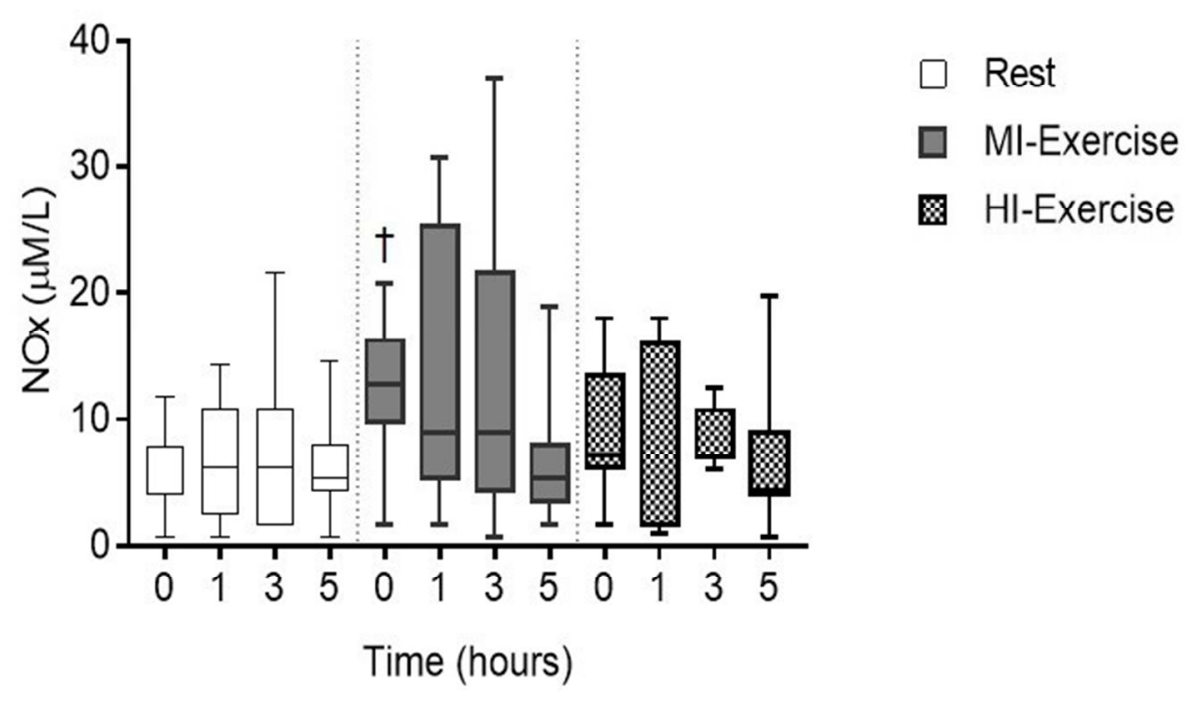

$62 \times 41 \mathrm{~mm}(300 \times 300 \mathrm{DPI})$ 


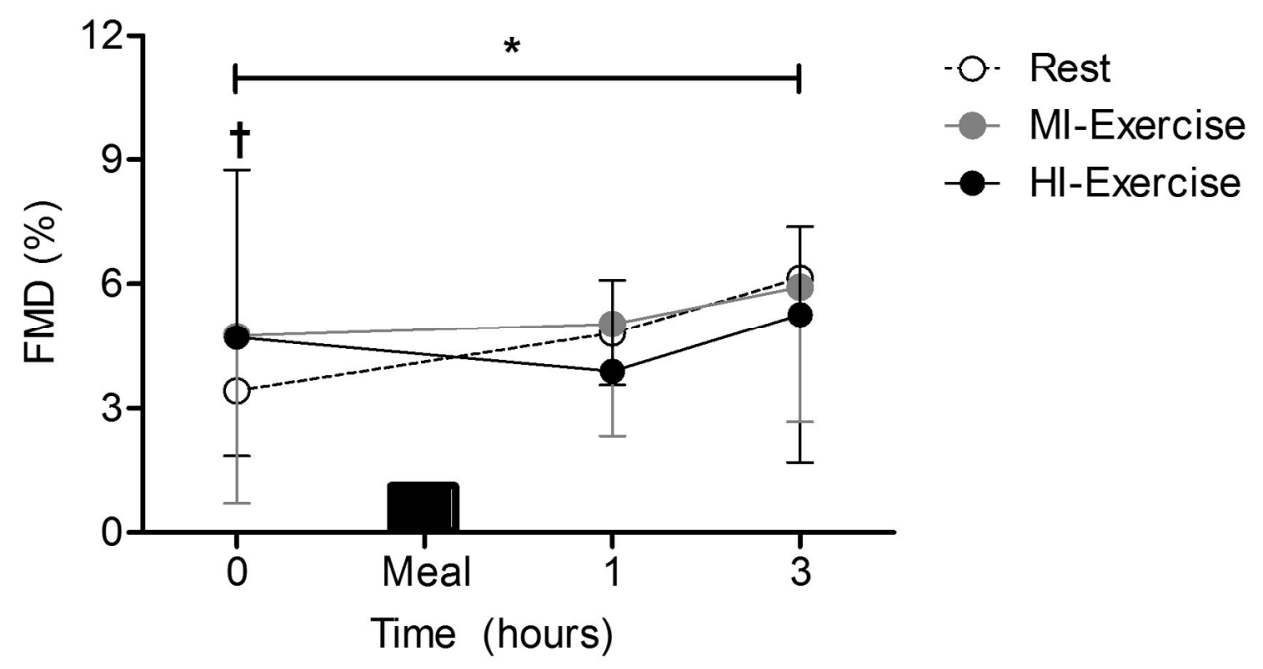

$160 \times 96 \mathrm{~mm}(300 \times 300$ DPI $)$ 